Muhammad, et al/Jurnal Ekonomi Syariah Teori dan Terapan Vol. 6 No. 1 Januari 2019: 142-153; PEMBINAAN NARAPIDANA DI LEMBAGA PEMASYARAKATAN MEDAENG, SURABAYA YANG DILAKUKAN OLEH LEMBAGA YDSF DENGAN MEMBERDAYAKAN DANA INFAQ

\title{
PEMBINAAN NARAPIDANA DI LEMBAGA PEMASYARAKATAN MEDAENG, SURABAYA YANG DILAKUKAN OLEH LEMBAGA YDSF DENGAN MEMBERDAYAKAN DANA INFAQ
}

\author{
Boby Ardyan Muhammad \\ Departemen Ekonomi Syariah -Fakultas Ekonomi dan Bisnis-Universitas Airlangga \\ Email: bobardyan@gmail.com \\ Tika Widiastuti \\ Departemen Ekonomi Syariah -Fakultas Ekonomi dan Bisnis-Universitas Airlangga \\ Email:widasus@yahoo.com
}

\begin{abstract}
:
The purpose of this research is to acknowledge the utilization of Yayasan Dana Sosial Al Falah's (YDSF) infaq funds and inmates' empowerment at Medaeng Correctional Facility. The motive behind this research is the phenomenon of inmates empowerment in the Medaeng Correctional Facility that is done by YDSF by utilizing infaq funds. Empowerment is purposed to develop inmates to become a better person in behavior, spirituality, and social connection. This research used a qualitative approach. The approach of this research is by using a case study method. Informants in this research are YDSF staff, correctional facility staff, and inmates. The data-gathering technique is done by data reduction, data presentation, and data conclusion. Findings in this research showed that infaq utilization affects the da'wah aspect, which is inmates empowerment in Medaeng correctional facility. This is not only developing inmates to become a better person but also their spirituality and religious activity, so when they have done their time, they will be easily accepted by the people.
\end{abstract}

Keywords: infaq, Empowerment, Development.

\section{PENDAHULUAN}

\section{Latar Belakang}

Islam sangat menganjurkan

umatnya untuk menghindari kesenjangan

di dunia, sehingga Islam menyeru

umatnya untuk menciptakan

kesejahteraan dan keadilan. Islam

memerintahkan umatnya untuk

mengeluarkan sebagian hartanya dalam

bentuk perintah yang spesifik di dalam Al-

Qur'an dan As-Sunnah. Perintah tersebut

dituliskan sebagai bentuk peringatan yang memiliki dua dimensi yakni, dimensi duniawi dan dimensi ukhrowi. Dimensi duniawi diinterpretasikan sebagai penekanan akan kesejahteraan hidup bagi dirinya dan orang lain, sedangkan dimensi ukhrowi menekankan kesejahteraan abadi setelah kematian. Sehingga Ven (2009) Menyebutkan Pengentasan kemiskinan dan penderitaan terletak di jantung Islam, hal ini dikarenakan pemberian zakat, infaq dan shadaqah sangat dianjurkan dalam Islam baik sebagai sarana pemurnian kekayaan seseorang dan untuk mengurangi kemiskinan dan penderitaan. Islam telah menempatkan mekanisme untuk mengentaskan kemiskinan dalam berbagai bentuk amal. Brooks (2007, dalam Muttaqin, 2015) menjelaskan bahwa pemberian sumbangan dalam bentuk uang kepada mereka yang membutuhkan, secara tidak langsung meningkatkan kesejahteraan mereka yang didukung oleh bukti empirik. Salah

1) Jurnal ini merupakan bagian dari Skripsi Boby Ardyan Muhammad, NIM: 041311433151, yang diuji pada tanggal 21 November 2019. 
Muhammad, et al/Jurnal Ekonomi Syariah Teori dan Terapan Vol. 6 No. 1 Januari 2019: 142-153; PEMBINAAN NARAPIDANA DI LEMBAGA PEMASYARAKATAN MEDAENG, SURABAYA YANG DILAKUKAN OLEH LEMBAGA YDSF DENGAN MEMBERDAYAKAN DANA INFAQ

satu bentuk amal dalam Islam yang juga menjadi instrumen ekonomi islam adalah infaq.

Infaq berasal dari kata anfaqa yang berarti menafkahkan, membelanjakan, memberikan atau mengeluarkan harta. Menurut istilah fiqh, kata infaq mempunyai makna memberikan sebagian harta yang dimiliki kepada orang yang telah diisyaratkan oleh agama untuk memberinya seperti orang-orang faqir, miskin, anak yatim, kerabat dan lain lain (Mardany, 2012:17).

Salah satu contoh nyata pemberdayaan infaq dalam pendidikan ialah program Yayasan Dana Sosial Al Falah bekerja sama dengan Lembaga Pemasyarakatan Medaeng mengadakan pembinaan untuk masyarakat lapas dengan tujuan memberi wawasan, pemahaman agama, pelatihan dan konseling. Program tersebut telah berjalan lebih dari sepuluh tahun.

Berdasarkan uraian di atas perlu dilakukan penelitian untuk mengkaji lebih lanjut terkait pemberdayaaninfaq yang dilakukan oleh lembaga Yayasan Dana Sosial Al-Falah (YDSF) untuk pembinaan narapidana di Lembaga Pemasyarakatan Medaeng. Agar mendapatkan hasil penelitian yang diharapkan maka peneliti perlu menyelidiki apa pengaruh dan dampak apa saja yang dihasilkandari adanya program pembinaan tersebut. Maka dari itu, penelitian ini megambil objek penelitian lembaga Yayasan Dana Sosial Al-Falah (YDSF) untuk diteliti lebih lanjut, sehingga judul penelitian ini adalah
"Peran Pemberdayaan Infaq di Lembaga YDSF Untuk Pembinaan Narapidana di Lembaga Pemasyarakatan Medaeng"

\section{Rumusan Masalah}

Berdasarkan latar belakang masalah yang telah diuraikan diatas, maka permasalahan yang dapat dirumuskan, adalah Bagaimana peran pemberdayaan infaq di lembaga YDSF untuk pembinaan narapidana di Lembaga Pemasyarakatan Medaeng?

\section{Tujuan Penelitian}

Tujuan penelitian ini adalah untuk menganalisis dan mengetahui untuk mengetahui peran pemberdayaan infaq di lembaga YDSF untuk pembinaan narapidana di Lembaga Pemasyarakatan Medaeng.

\section{LANDASAN TEORI}

Infaq berasal dari kata anfaqa yang berarti menafkahkan, membelanjakan, memberikan atau mengeluarkan harta. Menurut istilah figh, kata infaq mempunyai makna memberikan sebagian harta yang dimiliki kepada orang yang telah diisyaratkan oleh agama untuk memberinya seperti orang-orang faqir, miskin, anak yatim, kerabat dan lain lain (Mardany, 2012:17). Menurut terminologi syariat, infaq berarti mengeluarkan sebagian harta atau pendapatan atau penghasilan untuk suatu kepentingan yang diperintahkan ajaran Islam. (Hafidhuddin, 1998).Zakat diperuntukkan bagi 8 golongan, sebagaimana firman Allah SWT dalam surat At-Taubah ayat 60: 
Muhammad, et al/Jurnal Ekonomi Syariah Teori dan Terapan Vol. 6 No. 1 Januari 2019: 142-153; PEMBINAAN NARAPIDANA DI LEMBAGA PEMASYARAKATAN MEDAENG, SURABAYA YANG DILAKUKAN OLEH LEMBAGA YDSF DENGAN MEMBERDAYAKAN DANA INFAQ

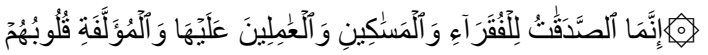

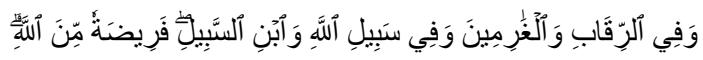

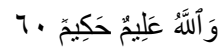

Artinya: Sesungguhnya zakat-zakat itu, hanyalah untuk orang-orang fakir, orangorang miskin, pengurus-pengurus zakat, Para mu'allaf yang dibujuk hatinya, untuk (memerdekakan) budak, orang-orang yang berhutang, untuk jalan Allah dan untuk mereka yuang sedang dalam perjalanan, sebagai suatu ketetapan yang diwajibkan Allah, dan Allah Maha mengetahui lagi Maha Bijaksana.

$$
\text { Infaq dalam bentuk yang umum }
$$

ialah mengorbankan harta pada jalan Allah SWT yang dapat menjamin segala kebutuhan manusia menurut tata cara yang diatur oleh hukum. Kewajiban berinfaq tidaklah terlepas pada zakat saja yang merupakan rukun Islam, akan tetapi disamping itu mengandung sesuatu keharusan berinfaq dalam memelihara dirinya dan keluarganya. Di dalam pemeliharaan umat dalam menjamin dan menolong terhadap kebaikan dan ketaqwaan (Bably, 1990). Arifin (2016) menjelaskan bahwa infaq adalah segala macam betuk pengeluaran (pembelanjaan) baik untuk kepentingan pribadi, keluarga, ataupun yang lain.

Ryandono dan Hazami (2016) menyebutkan ada tiga kunci sukses peran dan implementasi waqaf dalam pemberdayaan untuk peningkatan kesejahteraan masyarakat adalah; pertama, keberhasilan pembentukan karakter yang dimulai dengan pembianan sholatnya khususnya shalat lima waktu.
Kedua, keberhasilan dalam pembianaan mental spiritual antara lain; jiwa amanah, jujur, pekerja keras dan profesioanal. Ketiga, pendampingan dan monetoring selama penerimaan pembiayaan.

Menurut Peraturan Pemerintah No. 57 tahun 1999, bahwa Pembinaan adalah kegiatan untuk meningkatkan kualitas ketaqwaan kepada Tuhan Yang Maha Esa, intelektual, sikap dan perilaku, profesional, kesehatan jasmani dan rohani Narapidana dan Anak Didik Pemasyarakatan. John Dewey mengartikan pendidikan adalah "etimologically, the word education means just a process of leading or bringing up", artinya: "secara etimologi, kata pendidikan berarti suatu proses membimbing dan mendewasakan". Pendidikan juga dapat mengembangkan intelektual maupun akhlak anak didik yang dilaksanakan secara bertahap dengan memperhatikan usia maupun kemampuan anak. Sebagaimana pendapat J.B. Sykes, bahwa education dapat berarti "give intelectual and moral to a physical or mental faculty", artinya memberi latihan intelektual dan moral sampai pada latihan fisik, atau moral secara bertahap. (Mujib, 2010)

Surat Edaran Direktorat Jenderal Pemasyarakatan/Bina Tuna Warga No. KP.10.13/3/31, Pemasyarakatan sebagai Proses, maka hendaknya disalurkan dalam tahap demi tahap guna mengindari kegagalan daripada akibatakibat lain yang mana tidak diinginkan. Tahap-tahapnya sebagai berikut: 
Muhammad, et al/Jurnal Ekonomi Syariah Teori dan Terapan Vol. 6 No. 1 Januari 2019: 142-153; PEMBINAAN NARAPIDANA DI LEMBAGA PEMASYARAKATAN MEDAENG, SURABAYA YANG DILAKUKAN OLEH LEMBAGA YDSF DENGAN MEMBERDAYAKAN DANA INFAQ

Pertama, Hendaknya narapidana pada waktu akan datang ke Lapas dikenal dan diketahui dahulu apa kekurangan dan kelebihannya. Sebabsebab sampai ia melakukan tindak pidana, dan lain-lain hal tentang dirinya. Dengan bahan tersebut dapat direncanakan, lalu dilakukan usaha pembinaan terhadapnya.

Kedua, Bilamana pembinaan dari narapidana dan hubungan dengan masyarakat telah berjalan selaras selama 1/3 dari masa pidana yang sebenarnya dan menurut pendapat Dewan Pembinaan Pemasyarakatan sudah dicapai kemajuan dalam proses maka dapat dipindah ke Lapas medium security. Di tempat baru ini narapidana diberi tanggungjawab lebih besar, lebihlebih dalam tanggungjawab terhadap masyarakat luar, bersamaan pula untuk rasa harga diri, untuk mana sehingga masyarakat timbul kepercayaannya dan merubah sikapnya terhadap narapidana.

Ketiga, Jika sudah dijalani kurang lebih separuh masa pidana yang sebenarnya dan menurut Dewan Pembinaan Pemasyarakatan proses pemasyarakatan telah mencapai kemajuan yang lebih, baik mengenai narapidana maupun unsur-unsur masyarakat, maka wadah perlu diperluas, dimulai dengan usaha asimilasi narapidana pada kehidupan masyarakat lvar, seperti sekolah umum, beribadah, berolahraga dan lainnya. Segala masih dalam pengawasan dan bimbingan petugas pemasyarakatan.
Keempat, Akhirnya jika sudah menjalani $2 / 3$ dari masa pidana yang sebenarnya, sedikitnya 9 bulan dapat dilepaskan pelepasan bersayarat, kalau proses berjalan dengan lancar dan baik. Pada tahap ini wadah proses pemasyarakatan berupa masyarakat luar yang luas. Hidup dan kehidupan narapidana dengan unsur dari masyarakat telah menjadi positif dan merupakan suatu kebutuhan, suatu integritas.

Istilah pendidikan dengan pembinaan dengan alasan bahwa di dalam pembinaan agama Islam terdapat proses pendidikan agama Islam, sehingga pembinaan dan pendidikan ibarat dua sisi mata uang yang tak dapat dipisahkan. Pendidikan agama Islam, menurut Barnadib, adalah pendidikan dengan melalui ajaran-ajaran agama Islam, berupa bimbingan dan asuhan terhadap anak didik agar nantinya setelah selesai dari pendidikan ia dapat memahami, menghayati secara menyeluruh serta menjadikan ajaran agama Islam sebagai suatu pandangan di dalam hidupnya demi keselamatan hidup di dunia maupun di akherat.

Indikator

keberhasilan pemberdayaan dari dana zakat, infaq, dan sadaqah dalam bidang pendidikan dapat dilihat dari:

1. Aktifis Pergerakan

Membandingkan sikap peserta program Rumah Kepemimpinan sebelum dan sesudah diberikan pembinaan terpadu. Apakah 
Muhammad, et al/Jurnal Ekonomi Syariah Teori dan Terapan Vol. 6 No. 1 Januari 2019: 142-153; PEMBINAAN NARAPIDANA DI LEMBAGA PEMASYARAKATAN MEDAENG, SURABAYA YANG DILAKUKAN OLEH LEMBAGA YDSF DENGAN MEMBERDAYAKAN DANA INFAQ

setelah diberi pembinaan sikap peserta menjadi lebih peduli, sama saja atau malah menjadi lebih acuh terhadap keadaan lingkungan sosial. Kepedulian lingkungan kampus dan sosial masyarakat adalah bagaimana peserta dikondisikan untuk turut serta aktif dalam berbagai kegiatan di kampusnya atau lingkungan tempat tinggalnya dengan harapan peserta program dapat membantu memecahkan dan meringankan persoalanpersoalan yang ada di sosial masyarakat dalam lingkup yang kecil sekalipun.

2. Prestasi

Membandingkan prestasi peserta program sebelum dan sesudah diberikan pembinaan, apakah meningkat atau tidak. Prestasi yang dimaksut adalah prestasi dalam bidang pendidikan di kampus atau sekolahnya masingmasing, baik berupa juara lomba maupun Indeks Prestasi (IP).

3. Muslim Produktif

Membandingkan kegiatan ibadah peserta program apakah meningkat atau menurun setelah mendapat pembinaan. Muslim produktif adalah bagaimana menjadi seorang muslim yang tidak hanya menjalankan ibadah wajib seperti shalat lima waktu saja, lebih dari itu muslim produktif diartikan lebih dari sekadar yang wajib seperti mengikuti kajian Islam mingguan/bulanan, shalat di awal waktu, melakukan ibadah sunnah seperti tahajud, tilawah dan ibadah sunnah lainnya.

4. Kekeluargaan

Melihat tingkat kekeluargaan peserta saat menerima pembinaan, tidak dapat dibantah lagi manusia adalah mahluk sosial yang butuh satu sama lainnya. Dalam program pendidikan ini peserta harus tinggal ber-asrama satu sama lain berjumlah 35 orang dengan berbagai karakter yang berbeda, maka dari itu Peserta dituntut untuk lebih peduli dengan teman satu atapnya (Naufal,2017).

\section{METODE PENELITIAN}

Pendekatan yang dilakukan dalam penelitian ini menggunakan pendekatan kualitatif. Menurut Yin (2002:2) pendekatan kualitatif adalah pendekatan menggunkan data yang berupa kalimat tertulis atau lisan, peristiwa-peristiwa, pengetahuan atau proyek studi yang bersifat deskriptif. Spradley (1997:3) mengungkap bahwa pendekatan kualitatif adalah suatu proses penelitian dan pemahaman yang berdasarkan pada metodologi yang menyelidiki suatu fenomena, budaya sosial dan masalah manusia.

Penelitian ini bertujuan untuk menjawab rumusan masalah yaitu: "Bagaimana peran pemberdayaan infaa di lembaga YDSF untuk pembinaan narapidana di Lembaga Pemasyarakatan 
Muhammad, et al/Jurnal Ekonomi Syariah Teori dan Terapan Vol. 6 No. 1 Januari 2019: 142-153; PEMBINAAN NARAPIDANA DI LEMBAGA PEMASYARAKATAN MEDAENG, SURABAYA YANG DILAKUKAN OLEH LEMBAGA YDSF DENGAN MEMBERDAYAKAN DANA INFAQ

Medaeng, Surabaya?" Sehingga pertanyaan yang diajukan untuk penelitian ini adalah "bagaimana", lebih tepat untuk menggunakan pendekatan kualitatif, karena dalam penelitian ini peneliti tidak memiliki peluang untuk melakukan kontrol terhadap objek penelitian.

Strategi yang digunakan dalam penelitian ini adalah studi kasus deskriptif. Alasan penggunaan strategi studi kasus adalah :pertama, studi kasus memungkinkan hasil penelitian sulit dimanipulasi karena peneliti sulit mengontrol peristiwa-peristiwa yang sedang terjadi. Kedua, merupakan strategi yang sesuai dengan pertanyaan dalam penelitian ini. ketiga, fokus penelitian terletak pada fenomena penggunaan infaq dalam pembinaan narapidana di Lembaga Pemasyarakatan Medaeng, Surabaya, sehingga dibutuhkan bukan hanya data historis tetapi juga wawancara dan observasi lapangan. Keempat, batas-batas antara fenomena dan konteks tidak tampak dengan tegas. Kelima, terdapat proposisi atau arahan dan fokus penelitian yang dibangun pada proses awal penelitian (Yin,2008:18).

Ruang lingkup penelitian ini terbatas pada narapidana di Lembaga Pemasyarakatan Medaeng, Surabaya yang dibina oleh Yayasan Dana Sosial Al Falah (YDSF) melalui penghimpunan dana infaq. Penelitian ini terbatas hanya pada dampak dan pengaruh dari adanya fenomena pemberdayaan infaq untuk pembinaan narapidana di Lembaga Pemasyarakatan Medaeng, Surabaya. Penelitian ini dilakukan di Kecamatan Waru, Kabupaten Sidoarjo.

Indikator keberhasilan pemberdayaan dana infaq YDSF untuk pembinaan narapidana di lembaga pemasyarakatan Medaeng dalam penelitian ini mengacu pada indikator yang disebutkan oleh Naufal (2017) yang kemudian disesuaikan dengan konteks penelitian ini menjadi sebagai berikut:

1. Aktifis Pergerakan

Membandingkan sikap narapidana lembaga pemasyarakatan medaeng sebelum dan sesudah diberikan pembinaan. Apakah setelah diberi pembinaan sikap narpidana menjadi lebih peduli, sama saja atau malah menjadi lebih acuh terhadap keadaan lingkungan sosial. Kepedulian lingkungan lembaga pemasyarakatan dan sosial masyarakat adalah bagaimana narapidana dikondisikan untuk turut serta aktif dalam berbagai kegiatan di lembaga pemasyarakatan atau lingkungan tempat tinggalnya dengan harapan narapidana program pembinaan YDSF dapat membantu memecahkan dan meringankan persoalan-persoalan yang ada di sosial masyarakat dalam lingkup yang kecil sekalipun. 
Muhammad, et al/Jurnal Ekonomi Syariah Teori dan Terapan Vol. 6 No. 1 Januari 2019: 142-153; PEMBINAAN NARAPIDANA DI LEMBAGA PEMASYARAKATAN MEDAENG, SURABAYA YANG DILAKUKAN OLEH LEMBAGA YDSF DENGAN MEMBERDAYAKAN DANA INFAQ

2. Muslim Produktif

Membandingkan kegiatan ibadah narapidana program pembinaan apakah meningkat atau menurun setelah mendapat pembinaan. Muslim produktif adalah bagaimana menjadi seorang muslim yang tidak hanya menjalankan ibadah wajib seperti shalat lima waktu saja, lebih dari itu muslim produktif diartikan lebih dari sekadar yang wajib seperti mengikuti kajian Islam mingguan/bulanan, shalat di awal waktu, melakukan ibadah sunnah seperti tahajud, tilawah dan ibadah sunnah lainnya.

3. Kekeluargaan

Melihat tingkat kekeluargaan narapidana saat menerima pembinaan, tidak dapat dibantah lagi manusia adalah mahluk sosial yang butuh satu sama lainnya. Dalam program pendidikan ini narapidana harus melakukan kegiatankegiatan positif bersama-sama dengan narapidana lainnya agar tercipta kekeluargaan yang baik antara narapidana.

Jenis data yang digunakan dalam penelitian ini adalah data primer dan sekunder. Data primer adalah data yang diperoleh langsung dari sumbernya melalui wawancara dan observasi lapangan. Data primer merupakan data utama yang berasal dari hasil wawancara yang dilakukan secara mendalam oleh peneliti dan observasi lapangan. Data tersebut dikumpulkan dengan metode wawancara dimana memungkinkan peneliti bertatap muka secara langsung dengan informan dan menggali data dan informasi secara mendalam sehingga data dapat dipertanggungjawabkan validitasnya.

Data dalam penelitian ini didapatkan dari informan yang dipilih dengan tujuan untuk menggali informasi secara mendalam yang berhubungan dengan objek penelitian sehingga dapat memberikan keterangan yang akurat untuk menjawab masalah penelitian. Adapun kriteria informan yang akan diajukan untuk sumber informasi:

1. Narapidana di Lembaga Pemasyarakatan Medaeng, Surabaya

2. Staff di Lembaga Pemasyarakatan Medaeng, Surabaya

3. Staff YDSF

4. Merupakan orang yang mengetahui dengan seksama proses pemberdayaan dana infaq YDSF untuk pembinaan narapidana di Lembaga Pemasyarakatan Medaeng, Surabaya.

Teknik pengumpulan data yang dilakukan pada penelitian ini meliputi :

a. Survei Pendahuluan

Dalam penelitian ini observasi dan peninjauan awal terhadap Lembaga Pemasyarakatan Medaeng, Surabaya. Tujuan survei pendahuluan ini untuk mendapatkan gamabaran umum 
Muhammad, et al/Jurnal Ekonomi Syariah Teori dan Terapan Vol. 6 No. 1 Januari 2019: 142-153; PEMBINAAN NARAPIDANA DI LEMBAGA PEMASYARAKATAN MEDAENG, SURABAYA YANG DILAKUKAN OLEH LEMBAGA YDSF DENGAN MEMBERDAYAKAN DANA INFAQ

mengenai perilaku narapidana di Lembaga Pemasyarakatan Medaeng, Surabaya (Sugiyono, 2011:69).

b. Penelitian Lapangan

Dalam wawancara ini wawancara mendalam menjadi perangkat penting karena penelitian kualitatif lebih berupa kata-kata. " Tujuan dari wawancara jenis ini adalah untuk menemukan permasalahan secara lebih terbuka, dimana pihak yang diwawancarai diminta pendapat serta ide-ide" I Sugiyono,2011:233)

Penelitian ini dilakukan wawancara langsung terhadap pekerja di Lembaga Pemasyarakatan dan narapidana tersebut dijadikan informan. Informan yang diambil dianggap telah mengetahui bagaimana pendayagunaan infaquntuk pembinaan yang dilakukan pada Lembaga Pemsyarakatan tersebut.

Penelitian ini memilih narasumber atau informan yang dapat mempresentasikan dampak pembinaan narapidana lembaga pemasyarakatan Medaeng melalui pemberdayaan dana infaq YDSF. Dalam wawancara, dipilih wawancara semi terstruktur. Semi terstruktur termasuk dalam wawancara mendalam. Proses ini dilakukan hingga dapat menjawab rumusan masalah penelitian.

Peneliti mengumpulkan data primer dari wawancara mendalam pada informan yang telah dipilih. Materi wawancara yang telah dipersiapkan adalah pertanyaan yang berkembang sesuai dengan informan yang ditemui. Wawancara akan berakhir apabila telah sesuai dengan topik penelitian dan telah menjawab rumusan masalah penelitian. Hasil wawancara yang didapat nantinya akan didokumentasikan dengan disertai keterangan yang kemudian diintisarikan oleh peneliti.

c. Dokumentasi

\section{Dokumen} merupakan catatan peristiwa yang sudah berlalu. Kegiatan dokumentasi dilakukan dengan memanfaatkan dokumen sebagai sumber data agar memudahkan peneliti untuk menguji, menafsirkan, dan meramalkan yang sesuai dengan penelitian. Dokumen bisa berbentuk tulisan, gambar, atau karya-karya monumental dari seseorang. Hasil penelitian dari observasi atau wawancara akan lebih kredibel atau dapat dipercaya apabila didukung oleh suatu dokumentasi.

Penelitian kualitatif dengan strategi studi kasus bisa didasarkan atas enam sumber bukti yang 
Muhammad, et al/Jurnal Ekonomi Syariah Teori dan Terapan Vol. 6 No. 1 Januari 2019: 142-153; PEMBINAAN NARAPIDANA DI LEMBAGA PEMASYARAKATAN MEDAENG, SURABAYA YANG DILAKUKAN OLEH LEMBAGA YDSF DENGAN MEMBERDAYAKAN DANA INFAQ

dapat dijadikan fokus bagi pengumpulan data, adalah : dokumen, rekaman arsip, wawancara, observasi langsung, observasi pemeran, serta perangkat fisik (Yin,2013:103).

Teknik validasi yang digunakan dalam penelitian ini adalah triangulasi sumber data, yaitu membandingkan dan mengecek sumber yang didapat dari hasil wawancara dengan dua informan pihak Yayasan Dana Sosial Al-Falah (YDSF), satu informan petugas lembag pemasyarakatan dan tiga informan narapidana. Tiga teknik dalam analisis data di lapangan model Miles dan Huberman, yaitu:

1. Reduksi Data.

Data yang diperoleh melalui wawancara di lapangan harus segera diolah, karena jumlahnya yang tidak sedikit. Kemudian hasil rekaman wawancara tersebut diransformasi dalam bentuk transkip, wawancara tertulis, observasi, dan dokumenasi. Pada, tahap selanjutnya peneliti melakukan seleksi terhadap data yang akan disajikan di dalam hasil penelitian, dengan maksud data yang akan disajikan hanyalah data yang dibutuhkan dalam penelitian untuk memudahkan proses analisis.

2. Penyajian Data

Data disajikan dalam bemtuk teks naratif agar lebih mudah dipahami. Disisi lain data yang disajikan tidak selalu dalam bentuk teks naratif,
Sugiyono $(2015,249)$ menjelaskan bahwa, "dalam penelitian kualitatif penyajian data bisa dilakukan dalam bentuk uraian singkat, bagan, hubungan antar kategori, flowchart, dan sejenisnya". Bentuk teks naratif yang disajikan berupa data berisikan hasil wawancara dengan informan pihakYayasan Dana Sosial Al-Falah (YDSF), informan petugas lembaga pemasyarakatan dan informan narapidana.

3. Menarik Kesimpulan

Tahap yang terakhir adalah menarik kesimpulan. Penarikan kesimpulan berupa kegiatan interpretasi, yaitu menemukan makna data yang telah disajikan. Selanjutnya data dianalisis dalam bentuk kata-kata untuk mendiskripsikan fakta yang ada di lapangan atau untuk menjawab rumusan masalah penelitian ini tentang studi kasus pada pihak Yayasan Dana Sosial Al-Falah (YDSF).

\section{HASIL DAN PEMBAHASAN}

Berikut ini akan disampaikan hasil analisis penelitian selama melakukan proses penelitian yaitu meliputi tentang hasil analisis berdasarkan tiga indikator pemberdayaanterhadapap pembinaan narapidana di lembaga pemasyarakatan medaeng rutan klas $2 \mathrm{~A}$ dan dampaknya terhadap narapidana.

\section{A. Aktifis Pergerakan.}


Muhammad, et al/Jurnal Ekonomi Syariah Teori dan Terapan Vol. 6 No. 1 Januari 2019: 142-153; PEMBINAAN NARAPIDANA DI LEMBAGA PEMASYARAKATAN MEDAENG, SURABAYA YANG DILAKUKAN OLEH LEMBAGA YDSF DENGAN MEMBERDAYAKAN DANA INFAQ

Para narapidana dituntut untuk memiliki perilaku yang baik selama menjalani masa hukumannya di lembaga pemasyarakatan maupun nanti setelah selesai menjalani masa hukumannya yaitu saat keluar dari lembaga pemasyarakatan. Tujuannya yaitu agar narapidana dapat berperilaku baik lagi dan juga diterima di masyarakat luar dengan baik, nanti setelah keluar dari lembaga pemasyarakatan.

Selain itu para narapidana juga dituntut aktif dan rajin dalam mengikuti segala kegiatan yang ada di lembaga pemasyarakatan medaengr rutan klas 2A, baik itu kegiatan pembinaan YDSF maupun kegiatan-kegiatan lainnya yang diadakan oleh lembaga pemasyarakatan. Tujuannya yaitu agar narapidana lebih peka terhadap kejadian disekitarnya dan juga agar narapidana memiliki kegiatan selama menjalani masa hukumannya sehingga narapidana tidak menganggur yang mengakibatkan pikirannya kosong.

Karena keterbatasan data penulis hanya dapat mendapatkan informasi dari YDSF bahwa ada beberapa bahkan sudah mencapai banyak narapidana yang dulu mengikuti program pembinaan yang sekarang sudah keluar dari lembaga pemasyarakatan, sekarang menjalani kehidupannya dengan bekerja, hal ini membuktikan bahwa mereka sudah diterima kembali dimasyarakat luas. Dari informasidiatas menunjukkan bahwa YDSF sangat concern dalam membina narapidana terutama pada poin ini yakni berperilaku baik dan aktif sehingga dapat diterima kembali dimasyarakat luas dengan baik.

\section{B. Muslim Produktif}

Para narapidana dituntut untuk menjaga dan menambah segala ibadah wajib secara berjamaah dan juga melakukan ibadah-ibadah sunnah lainnya seperti mengaji,hafalan doa-doa dan ber amal, selain itu narapidana juga dibantu untuk memiliki suatu keahlian tertentu sebagai bentuk bagaimana kita sebagai umat muslim harus produktif dan tidak boleh bermalas-malas an. Tujuannya adalah narapidana muslim kembali menemukan jati diri mereka yaitu menjadi umat muslim yang baik dan menjalankan segala kewajibannya, keseharian narpidana juga banyak diisi dengan kegiatan keagamaan agar kerohanian narapidana menjadi semakin agamis dan lebih baik lagi, dan juga agar narapidana dapat menjadi muslim yang baik, taat dan produktif nantinya ketika sudah selesai menjalani masa hukumannya di lembaga pemasyarakatan yaitu saat keluar dari lembaga pemasyarakatan.

\section{Kekeluargaan}

Tinggal dengan jumlah orang yang banyak dengan kepribadian yang dapat dikatakan jauh berbeda menjadi tantangan bagi para narapidana, ada yang pendiam bahkan cenderung menutup diri dan ada pula yang ramai dan bisa membuka diri bahkan membaur dengan mudah, namun mereka harus tetap bersosialisasi dengan banyaknya narapidana lain agar dapat bertahan 
Muhammad, et al/Jurnal Ekonomi Syariah Teori dan Terapan Vol. 6 No. 1 Januari 2019: 142-153; PEMBINAAN NARAPIDANA DI LEMBAGA PEMASYARAKATAN MEDAENG, SURABAYA YANG DILAKUKAN OLEH LEMBAGA YDSF DENGAN MEMBERDAYAKAN DANA INFAQ

dan menjalani masa hukuman di lembaga pemasyarakat dengan baik.

Saat pertama kali masuk lembaga pemasyarakatan, hampir semua para narapidana pasti merasakan kaget dan emosi yang tidak terkendali dan meluapmeluap, namun dengan adanya program pembinaan YDSF ini narapidana dituntut untuk menjadi pribadi yang bersosialisasi dengan baik dan memiliki sifat kekelvargaan. Hal ini terbukti dari bagaimana mereka sangat peduli dengan lingkungan dan teman-teman yang mereka anggap senasib, serta minim nya terjadi perselisihan antar narapidana, sering dan aktifnya mereka aktif dalam mengikuti setiap kegiatan dari program pembinaan YDSF adalah salah satu faktor terbesar terbentuknya sifat kekeluargaan mereka yang sampai saat ini tujuan dari indikator kekeluargaan ini sudah sangat terpenuhi.

\section{KESIMPULAN}

Berdasarkan

hasil dan pembahasan penelitian tersebut, dapat ditarik beberapa kesimpulan, yaitu:

Berdasarkan analisis dan pembahasan yng telah dijelaskan oleh penulis dalam bab sebelumnya maka dilihat dari pemberdayaannya YDSF dan Lembaga Pemasyarakatan Medaeng Rutan Klas 2A yang memberdayakan dana infaq ke salah satu program dakwah yaitu program pembinaan narapidana. Peran pemberdayaan ditunjukkan dengan tercapainya tiga unit analisis sebagai indikator keberhasilan program.
Melalui program pembinaan yang diterima narapidana dapat memperbaiki diri menjadi lebih baik dari sisi perilaku, kerohanian, dan hubungannya dengan orang lain sekarang dan nanti saat sudah keluar dari lembaga pemasyarakatan dan kembali menjalani kehidupan dimasyarakat luas, sehingga mampu mewujudkan tujuan awal dibentuknya program pembinaan oleh YDSF untuk narapidana di Lembaga Pemasyarakatan Medaeng Rutan Klas 2A yaitu membantu para narapidana untuk menemukan kembali kehidupannya yang baik dan juga mendapatkan ridha Allah SWT.

Adapun indikator yang telah ditentukan oleh lembaga YDSF yaitu aktifis pergerakan, muslim produktif, dan kekeluargaan. Indikator aktifis pergerakan sudah dicapai oleh narapidana, hal ini dibuktikan dari narapidana sudah berperilaku baik, aktif dalam seluruh kegiatan di lembaga pemasyarakatan Medaeng, dan bisa mengendalikan emosinya dengan baik. indikator muslim produktif sudah dicapai oleh narapidana, hal ini dibuktikan dari narapidana sudah meningkatkan kerohaniannya dengan melaksanakan sholat 5 waktu, mengaji, dan hafalan surat-surat Al-qur'an. Dan yang terakhir indikator kekeluargaan juga sudah dicapai narapidana, hal ini dibuktikan dari narapidana sudah 
Muhammad, et al/Jurnal Ekonomi Syariah Teori dan Terapan Vol. 6 No. 1 Januari 2019: 142-153; PEMBINAAN NARAPIDANA DI LEMBAGA PEMASYARAKATAN MEDAENG, SURABAYA YANG DILAKUKAN OLEH LEMBAGA YDSF DENGAN MEMBERDAYAKAN DANA INFAQ

memiliki hubungan sosial yang baik dengan lingkungannya.

\section{DAFTAR PUSTAKA}

Bably, Muhammad. M. 1990. Kedudukan Harta Menurut Pandangan Islam.Terj. Abdul Idris. Jakarta.

Hafidhuddin, D. 1998. Panduan Praktis tentang Zakat, Infaq, dan Shadaqah.Jakarta: gema Insani.

Mardany. 2012. Figh Mu'amalah. Jakarta: Kencana Media Group.

Priliyanti, Indah. 2010. Transformasi Tradisi Filantropi Islam : Studi Model Pendayagunaan Zakat, Infaq, sadaqah, Wakaf di indonesia. Jurnal Economica. No. 11/ Edisi II/ November 2010.

Mustofa, Muhammad. 2007. Kriminologi kajian sosiologi terhadap kriminalitas perilaku menyimpang dan pelanggaran hukum. Depok: FISIP UI Press.

Direktorat Jenderal LAPAS. 2008. Cetak biru pembaharuan pelaksanaan sistem LAPAS. Jakarta: Departemen Hukum dan Hak Asasi Manusia Direktorat Jenderal LAPAS.

Direktorat Jendral Pemasyarakatan, 2009:11

Teuku A, 2017. Peran Pemberdayaan Dana Zakat, Infaq dan Shadaqah Dalam Bidang Pendidikan (studi kasus: Yayasan Dana Sosial AlFalah dan Rumah Kepemimpinan Surabaya).Skripsi. Tidak Diterbitkan. Fakultas Ekonomi dan Bisnis. Universitas Airlangga.
Moloeng, Lexy. 2012. Metodologi Penelitian Kualitatif. Jakarta. Remaja Rosdakarya

Sugiyono. 2011. Metode Penelitian Kuantitatif, Kualitatif dan R\&D. Bandung: Afabeta

Sugiyono. 2012. Metode Penelitian Kuantitatif, kualitatif dan $R$ \& $D$. Bandung. Alfabeta.

Miles, M.B., dan Michael Huberman. 2009. Analisis Data Kualitatif Buku Sumber Tentang Metode-Metode Baru. Jakarta. UI Press.

\section{Peraturan Perundang-undangan:}

Undang-Undang No. 12 Tahun 1995 tentang Pemasyarakatan

Peraturan Pemerintah No. 31 Tahun 1999 tentang Pembinaan dan Pembimbingan Warga Binaan Pemasyarakatan. 